\title{
The economic determinants of interest rate option smiles
}

\author{
Prachi Deuskar ${ }^{\mathrm{a}, 1}$, Anurag Gupta ${ }^{\mathrm{b}, 2}$, Marti G. Subrahmanyam ${ }^{\mathrm{c}, *}$ \\ ${ }^{a}$ Department of Finance, College of Business, University of Illinois at Urbana-Champaign, 304C David Kinley Hall, \\ 1407 West Gregory Drive, Urbana, IL 61801, United States \\ ${ }^{\mathrm{b}}$ Department of Banking and Finance, Weatherhead School of Management, Case Western Reserve University, 10900 Euclid Avenue, \\ Cleveland, OH 44106-7235, United States \\ ${ }^{c}$ Department of Finance, Leonard N. Stern School of Business, New York University, 44, West Fourth Street \#9-15, \\ New York, NY 10012-1126, United States
}

Received 22 November 2006; accepted 18 May 2007

\begin{abstract}
We address three questions relating to the interest rate options market: What is the shape of the smile? What are the economic determinants of the shape of the smile? Do these determinants have predictive power for the future shape of the smile and vice versa? We investigate these issues using daily bid and ask prices of euro $(€)$ interest rate caps/floors. We find a clear smile pattern in interest rate options. The shape of the smile varies over time and is affected in a dynamic manner by yield curve variables and the future uncertainty in the interest rate markets; it also has information about future aggregate default risk. Our findings are useful for the pricing, hedging and risk management of these derivatives.
\end{abstract}

(C) 2007 Elsevier B.V. All rights reserved.

JEL classification: G10; G12; G13; G15

Keywords: Volatility smiles; Interest rate options; Euro interest rate markets; Euribor market

\section{Introduction}

Over-the-counter interest rate options such as caps/ floors are among the most liquid options that trade in the global financial markets, with about $\$ 37$ trillion of notional principal and $\$ 580$ billion in gross market value outstanding as of June 2006. ${ }^{3}$ Given the enormous size of these markets, significant effort has been devoted, both in academia and in industry, to the development and testing

\footnotetext{
* Corresponding author. Tel.: +1 212998 0348; fax: +1 2129954233.

E-mail addresses: pdeuskar@uiuc.edu (P. Deuskar), anurag.gupta@case.edu (A. Gupta), msubrahm@stern.nyu.edu (M.G. Subrahmanyam).

${ }^{1}$ Tel.: +1 217244 0604; fax: +1 2172449867 .

2 Tel.: +1 216368 2938; fax: +1 2163686249 .

${ }^{3}$ BIS Quarterly Review, December 2006, Bank for International Settlements, Basel, Switzerland.
}

of models to accurately price and hedge these claims. ${ }^{4}$ However, most of these studies have focused on at-themoney options, with little attention paid to the determinants of volatility smiles/skews in interest rate options markets. ${ }^{5}$ In this paper, we address this issue in the euro $(€)$ interest rate options market by characterizing the smile, its time variation and its economic determinants. We also examine the information content of interest rate option smiles, in order to understand whether it has any statistical power in predicting specific macro-economic variables.

Volatility smiles are an extensively documented crosssectional feature in the equity options markets, ever since

\footnotetext{
${ }^{4}$ These include Driessen et al. (2003), Fan et al. (2003), Longstaff et al. (2001), Peterson et al. (2003), and many others.

${ }^{5}$ Gupta and Subrahmanyam (2005). Jarrow et al. (2007) do examine smile effects in interest rate options, but only from a modeling perspective.
} 
they were first reflected in option prices after the October 1987 stock market crash. Indeed, the focus of much of the research in the equity options literature has primarily been to relax the assumptions of the Black-Scholes valuation framework to model the volatility smile patterns observed in the market. The frameworks proposed have evolved from models with deterministically varying volatility of returns to models that incorporate either stochastic volatility, or jumps in the underlying price process, or both. ${ }^{6}$ In spite of their increasing complexity, none of these models has been successful in accurately explaining the behavior of the observed volatility smiles - the empirically observed smiles are typically more perceptible than those predicted by theory. Effort has also been devoted to explaining the volatility smile in equity options markets using liquidity effects or market frictions, with some success. ${ }^{7}$ However, very little research has been conducted on directly examining the economic determinants of the volatility smile patterns in the options markets. An exception is the paper by Pena et al. (1999), who examine the determinants of the implied volatility function in the Spanish equity index options market.

In contrast to the literature on equity options, research on the smile in the interest rate options market has been quite sparse. The sole exception is a paper by Jarrow et al. (2007) who examine the smile in US dollar caps and floors, and find that even models augmented with stochastic volatility and jumps do not fully capture the smile.

The conclusions from equity options markets cannot be readily extended to interest rate option markets, since these markets differ significantly from each other for several reasons. First, in contrast to equity option markets, interest rate option markets are almost entirely institutional, with hardly any retail presence. Most interest rate options, particularly the long-dated ones such as caps, floors and swaptions, are sold over-the-counter (OTC) by large market makers, typically international banks. The customers are usually on one side of the market (the ask-side), and the size of individual trades is relatively large. Second, many popular interest rate option products, such as caps, floors and collars are portfolios of options, from relatively short-dated to extremely long-dated ones. These features lead to significant issues relating to supply/demand and asymmetric information that are different from those for exchange traded equity options. Third, since interest rate options are traded in an OTC market, there are also important credit risk issues that may influence the pricing of these options, especially during periods of crisis. Therefore, inferences drawn from studies in the equity option markets are not directly relevant for interest rate option markets, although there may be some broad similarities.

\footnotetext{
${ }^{6}$ See Bakshi et al. (1997), Dumas et al. (1998), Bates (2000) and several references therein for more on this literature.

${ }^{7}$ See Ederington and Guan (2002), Mayhew (2002), Pena et al. (1999, 2001), Bollen and Whaley (2004), Garleanu et al. (2006), for example.
}

Given the limited success of attempts to model the distribution of the underlying to explain the smile, we adopt a different approach. We seek to directly examine the economic determinants of the smile. To give an analogy, our approach is similar to finding empirical risk factors as opposed to calibrating utility-based models in order to explain the cross-section of stock returns, in the asset pricing literature. In this paper, we contribute to the literature in three distinct ways. First, we present an extensive documentation of the volatility smile patterns in the interest rate options markets for different maturities, separately for the bid and the ask-sides of the market. Second, we explore the determinants of volatility smiles in these markets, in terms of macro-economic and liquidity variables. Third, we examine the bidirectional Granger-causality between volatility smiles and the macro-economic and liquidity variables to understand the dynamic nature of these relationships.

We find that there are clearly perceptible volatility smiles in caps and floors, across all maturities. Short-term caps and floors exhibit smiles that are significantly steeper than those for longer-term caps and floors. Long-term options display more of a "smirk" than a smile. Measures of the shape of the volatility smile (slope and curvature) are significantly related to term structure variables. In particular, the curvature of the smile is positively related to the 6month interest rate for shorter maturity options and negatively related to the slope of the term structure for longer maturity options. This suggests that away-from-the-money options, especially of shorter maturity, are significantly more expensive (compared to at-the-money options), during higher interest rate regimes. On the other hand, the away-from-the-money options are comparatively less expensive when the term structure is relatively flat. Our results for the slope of the volatility smile show that outof-the money caps (floors) become disproportionately more expensive when interest rates go up (down). This may be a result of the existence of price pressure in this market induced by hedging demand from customers, consistent with some of the results reported in Bollen and Whaley (2004) and Garleanu et al. (2006). Alternatively, the slope of the yield curve may capture the skew of the distribution of future interest rate, and thus affect the slope of the smile. These relationships between the term structure variables and the smile variables also hold for their innovations.

In addition, we find that high-volatility periods are associated with flatter volatility smiles, suggesting a stochastic volatility framework with mean reversion in volatility. We also find evidence that the curvature of the smile for longer maturity options is positively related to the liquidity costs in this market, as proxied by the bid-ask spreads. We conjecture that, perhaps, liquidity effects could account for a part of the smile, especially for longer maturity options.

We use multivariate Granger-causality tests to examine if lagged values of any of the explanatory variables can predict the curvature and asymmetry of the volatility smile and vice versa. We find that the 6-month interest rate 
Granger-causes the slope and the curvature of the volatility smile, while the slope of the term structure Granger-causes the curvature of the smile curve. We also find that slope of the volatility smile curve can predict the aggregate default spread, even after controlling for the persistence in the default spread, and in the lagged values of yield curve variables. The impulse response function shows that a positive shock to the slope of the smile of shorter maturity options is followed by an increase in the default spread. This is intuitive because a higher slope of the smile implies higher relative prices of out-of-the-money floors that hedge the risk of falling interest rates, which are associated with an economic downturn and higher default risk, and thus, an increase in the default spread.

The results of our paper have important implications for the modeling and risk management of interest rate derivatives, especially options. We find that even after controlling for the persistence in the shape of the smile, lags of the 6month interest rate and the slope of the yield curve have information about future shapes of the smile. Usually, while calibrating the interest rate option models, only the contemporaneous yield curve is used. Our results suggest that using lagged values of the short-term interest rate and the slope of the yield curve could improve the calibration of these models. This is intuitive if the future distribution of interest rates is not fully captured by today's yield curve, but, in addition, depends on the past values of interest rates. Our results also have implications for the modeling of credit derivatives, whose payoffs depend on the default spread, since we find that the shape of the smile can predict the default spread.

The structure of our paper is as follows. Section 2 describes the data set and presents summary statistics. Section 3 presents the empirical patterns of the volatility smile that we observe in the data. In Section 4, we examine the impact of several macro-economic variables on these patterns. Section 5 presents the results of the multivariate vector autoregression and the Granger-causality tests. Section 6 concludes with a summary of the main results and directions for future research.

\section{Data}

The data for this study consist of prices of euro $(€)$ caps and floors over the 29-month period, January 1999 to May 2001, obtained from WestLB (Westdeutsche Landesbank Girozentrale) Global Derivatives and Fixed Income Group. These are daily bid and offer quotes over 591 trading days for nine maturities ( 2 years to 10 years, in annual increments) across twelve different strike rates ranging from $2 \%$ to $8 \%$. This is an extensive set with price quotes for caps and floors every day, reflecting the maturity-strike combinations that elicit market interest on that day.

WestLB is one of the dealers who subscribe to the interest rate option valuation service from Totem. Totem is the leading industry source for asset valuation data and ser- vices, supporting independent price verification and risk management in the global financial markets. Most leading derivative dealers subscribe to their service. As part of this service, Totem collects data for the entire range of caplets and floorlets across a series of maturities from these dealers. They aggregate this information and return the consensus values back to the dealers who contribute data to the service. The market consensus values supplied to the dealers include the underlying term structure data, caplet and floorlet prices, as well as the prices and implied volatilities of the reconstituted caps and floors across strikes and maturities. Hence, the prices quoted by dealers such as WestLB, who are a part of this service, reflect the market-wide consensus information about these products. This is especially true for plain-vanilla caps and floors, which are very high-volume products with standardized structures, that are also used by dealers to calibrate their models for pricing and hedging exotic derivatives. Therefore, it is extremely unlikely that any large dealer, especially one that uses a market data integrator such as Totem, would deviate systematically from market consensus prices for these vanilla products. ${ }^{8}$ Our discussions with market participants confirm that the prices quoted by different dealers (especially those that subscribe to Totem) for vanilla caps and floors are generally similar.

Interest rate caps and floors are portfolios of European interest rate options on the 6-month Euribor with a 6 monthly reset frequency. ${ }^{9}$ In addition to the options data, we also collected data on euro $(€)$ swap rates and the daily term structure of euro interest rates curve from the same source. These are the key inputs necessary for checking cap-floor parity, as well as for conducting our subsequent empirical tests. We calculate the "moneyness" of the options by estimating the log moneyness ratio (LMR) for each cap/floor. The LMR is defined as the logarithm of the ratio of the par swap rate to the strike rate of the option. Since the relevant swap rate changes every day, the LMR of options at the same strike rate and maturity also changes each day.

We pool the data on caps and floors to obtain a wider range of strike rates, on both sides of the at-the-money strike rate. Before doing so, we check for put-call parity

\footnotetext{
${ }^{8}$ The euro OTC interest rate derivatives market is extremely competitive, especially for plain-vanilla contracts like caps and floors. The BIS estimates the Herfindahl index (sum of squares of market shares of all participants) for euro interest rate options (which includes exotic options) at about 500-600 during the period from 1999 to 2004, which is even lower than that for USD interest rate options (around 1,000). Since a lower value of this index (away from the maximum possible value of 10,000) indicates a more competitive market, it is safe to rely on option quotes from a top European derivatives dealer (reflecting the best market consensus information available with them) like WestLB during our sample period. Thus, any dealer-specific effects on price quotes are likely to be small and unsystematic across the over 30,000 bid and ask price quotes each that are used in this paper.

${ }^{9}$ For the details of the contract structure for caps and floors, please refer to Longstaff et al. (2001) for the US dollar market and to Deuskar et al. (2007) for the Euro market.
} 
between caps, floors and swaps, using both bid and ask prices. We find that, on average, put-call parity holds in our dataset, although there are deviations from parity for some individual observations. ${ }^{10}$ These parity computations are a consistency check, as well, to assure us about the integrity of our dataset.

\section{Shapes of the volatility smile in interest rate option markets}

We use implied volatilities from the Black-BGM (Black, 1976; Brace et al., 1997 (BGM)) model, throughout the analysis. We do so for two reasons. First, although there may be an alternative complex model that explains at least part of the smile/skew or the term structure of volatility, it is necessary to obtain an initial sense of the empirical regularities using the standard model. In other words, we need to document the characteristics of the smile before attempting to model it formally. ${ }^{11}$ Furthermore, the evidence in the equity option markets suggests that even such complex models may not explain the volatility smile adequately, without considering the effect of market frictions. Second, Black-BGM implied volatilities are the common market standard for dealer quotations for interest rate option prices.

We document volatility smiles in euro interest rate caps and floors across a range of maturities using the implied "flat" volatilities of caps and floors over our sample period. The flat volatility is a volatility number common to all the caplets (floorlets) in a cap (floor), which sets the sum of their prices equal to the quoted price for the cap (floor). Thus the flat volatility is a weighted average of the implied volatility of individual options included in a cap or a floor. ${ }^{12}$ Furthermore, we scale the implied volatility of the cap/floor by the at-the-money volatility of the midprice (average of bid and ask price) of the cap of the same maturity (and call it Scaled IV). This scaling accounts for the effect of changes in the level of implied volatilities over time. Scatter plots of the Scaled IV against the LMR for interest rate options in this market indicate a significant

\footnotetext{
${ }^{10}$ Many of these deviations may not be actual violations from parity, given the difficulty in carrying out the arbitrage using "off-market" swaps. Since the bid and ask prices of "off-market" swaps are not available, we cannot examine which of these observations is a real violation of put-call parity.

${ }^{11}$ The use of implied volatilities from the Black-Scholes model is in line with all prior studies in the literature, including Bollen and Whaley (2004).

${ }^{12}$ Our implied volatility estimation is likely to have much smaller errors than those generally encountered in equity options (see, for example, Canina and Figlewski, 1993). We pool the data for caps and floors, which reduces any error due to mis-estimation of the underlying yield curve. The options we consider have much longer maturities (the shortest cap/floor is 2 year maturity), which reduces this potential error further. In addition, for most of our empirical tests, we do not include deep ITM or deep OTM options, where estimation errors are likely to be larger. Furthermore, since we consider the implied flat volatilities, the errors are further reduced due to the implicit "averaging" in this computation.
}

smile curve that is approximately quadratic and steeper for shorter maturity options than longer maturity ones. ${ }^{13,14}$

\subsection{Functional forms for implied volatility smiles}

Next, we estimate various functional forms for volatility smiles using pooled time-series and cross-sectional ordinary least squares regressions, in order to understand the overall form of the volatility smile over our entire sample period. The most common functional forms for the volatility smile used in the literature are quadratic functions of either moneyness or the logarithm of moneyness. In addition, the scatter plots of Scaled IV against LMR suggest a quadratic form. Therefore, we estimate the following functional form:

Scaled IV $=c 1+c 2 * \mathrm{LMR}+c 3 * \mathrm{LMR}^{2}$.

We also estimate an asymmetric quadratic functional form, where the slope is allowed to differ for in-the-money and out-of-the-money options, with similar results. (Polynomials of higher order turn out to be statistically insignificant.) In addition, we estimate the volatility smiles on the bid-side and the ask-side separately. Using the mid-point of the bid-ask prices may not always accurately display the true smile in the implied volatility functions, given that bidask spreads differ across strike rates.

Fig. 1 presents the plots of fitted implied volatility functions based on specification (1) for caps and floors separately for different maturities. These plots clearly show a smile curve for these options and display some interesting patterns. Caps always display a smile, which flattens as the maturity of the cap increases. In-the-money caps $($ LMR $>0)$ have a significantly steeper smile than out-ofthe-money caps. More interestingly, the ask-side of the smile is steeper than the bid-side, the difference being significantly larger for in-the-money caps. Floors display somewhat similar patterns. The smile gets flatter as the maturity of the floor increases. In-the-money floors $(\mathrm{LMR}<0)$ exhibit a significantly steeper smile, especially for short-term floors. Long-term floors display almost a "smirk", instead of a smile. As with caps, the smile curve for floors is steeper on the ask-side, as compared to that on the bid-side.

\footnotetext{
${ }^{13}$ The scatter plots have not been presented in the paper to save space, and are available from the authors.

${ }^{14}$ In addition, we analyze the principal components of the changes in the Black volatility surface (across strike rates and maturities) for caps and floors. If away-from-the-money option prices were just mechanical transformations of ATM option prices, we would observe a very high proportion of the variation in these implied volatilities being explained by just one principal component. However, we find four significant principal components on the ask-side and two on the bid-side, indicating that the implied volatilities for away-from-the-money options are not just being adjusted by the dealer using a mechanical rule anchored by the at-themoney volatilities.
} 
2 year caps

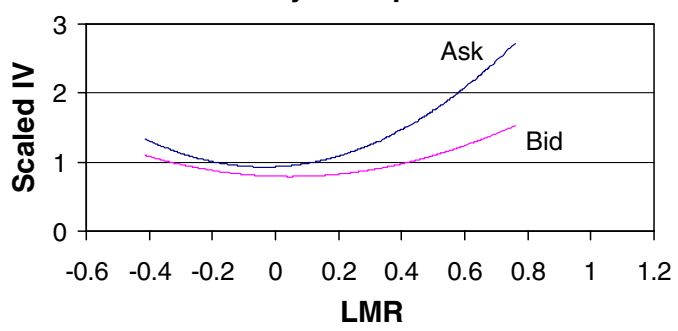

5 year caps

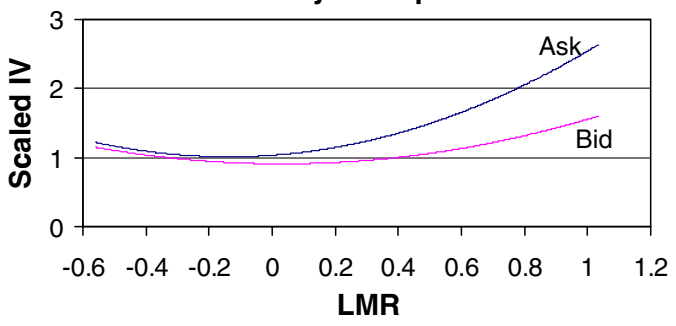

10 year caps

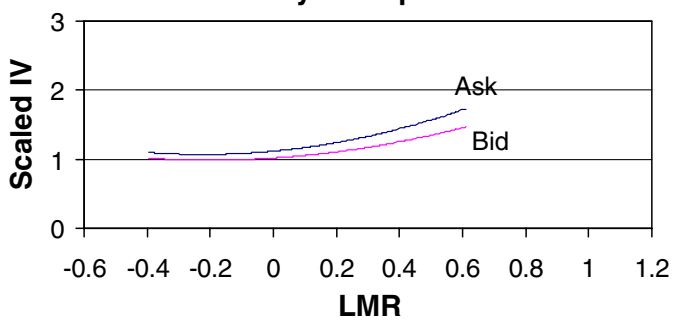

2 year floors

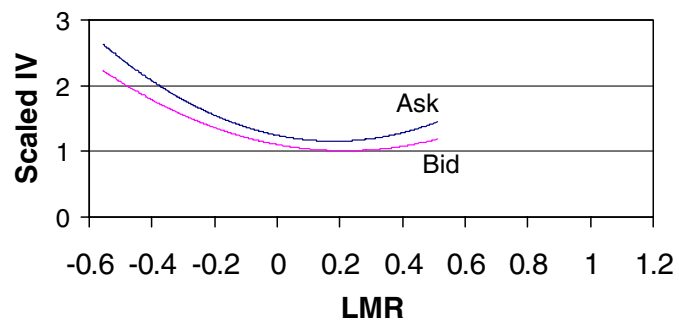

5 year floors

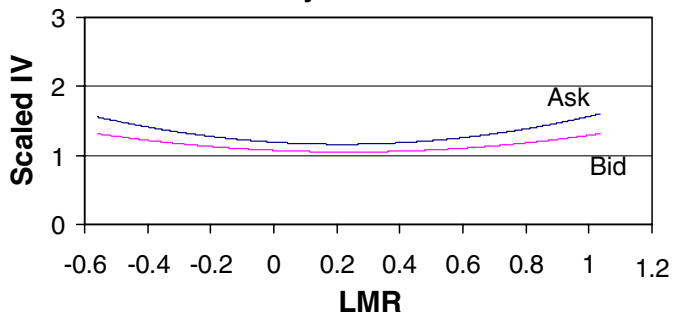

10 year floors

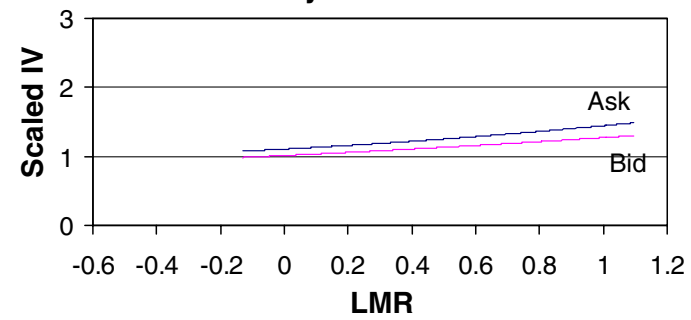

Fig. 1. Functional forms of implied volatility smiles in interest rate caps and floors. This figure presents the fitted smile functions for the bid and ask implied flat volatilities of euro interest rate caps and floors separately, across different maturities. The horizontal axis in the plots corresponds to the logarithm of the moneyness ratio (LMR), defined as the ratio of the par swap rate to the strike rate of the option. The vertical axis in the plots corresponds to the implied flat volatility of the bid and ask prices of the option, scaled by the at-the-money volatility for the option of similar maturity (Scaled IV). The fitted values are calculated using a quadratic function of LMR as in specification (1). The plots are three representative maturities - 2-year, 5-year, and 10year for the period, Jan 99 - May 01, for various maturities, based on data obtained from WestLB Global Derivatives and Fixed Income Group.

In Table 1, we report the results for caps and floors pooled together for specification (1). The regression coefficients in almost all the maturities are highly significant. In addition, the quadratic functional form explains a high proportion of the variability in the scaled implied volatilities. ${ }^{15}$ The coefficient of the curvature of the smile decreases with the maturity of the options, indicating that as the maturity of these options increases, the smile flattens, and eventually converts into a "smirk" when we reach the 10year maturity. In addition, we re-estimate these specifications using a volatility and maturity adjusted moneyness measure $(\log ($ Swap RatelStrike Rate $) /($ ATM Volatility*(Maturity $\left.)^{1 / 2}\right)$ ) instead of LMR), similar to the one used in Carr and Wu (2003a,b), Li and Pearson (2004). We still observe similar smile patterns, with a flattening of the smile curve with maturity, consistent with the findings of Backus et al. (1997) for currency options, where

\footnotetext{
${ }^{15}$ We also conducted the same exercise with spot volatilities i.e. using inferred prices of individual caplets and floorlets, obtained by bootstrapping from the flat volatilities of caps and floors. Model (1) fits well there as well. Those results are not presented here to conserve space.
}

they find that the smile flattens with maturity even using the adjusted moneyness measure. ${ }^{16}$

\subsection{Time variation in volatility smiles}

In Fig. 2, we present the surface plots for the fitted values of the scaled implied volatilities against moneyness represented by the LMR using specification (1) to fit a smile every day. ${ }^{17}$ The shapes of these surface plots show

\footnotetext{
${ }^{16}$ We also plotted the scaled and unscaled implied volatilities, respectively against the volatility and maturity adjusted moneyness measure. (These plots are not included in the paper to conserve space, and are available from the authors, upon request.) Longer maturity caps and floors still have a flatter smile, so the transformation of the moneyness scale does not appear to change the pattern of the smiles across maturities. In addition, these scatter plots are very similar to the ones that use LMR as the moneyness measure. Therefore, in the Euro interest rate options markets, the shape of the smile appears to be the same regardless of the measure of moneyness, simple or adjusted.

17 These plots are presented for representative maturities of 2-, 5-, and 10years, since the plots for the other maturities are similar. In addition, we present the fitted volatility smiles over the LMR range from -0.3 to +0.3 , which is the subset of strikes over which we have enough observations to estimate specification (1) over a substantial number of days in our dataset.
} 
Table 1

Functional forms for implied volatility smiles

\begin{tabular}{lllll}
\hline Maturity & $\mathrm{c} 1$ & $\mathrm{c} 2$ & $\mathrm{c} 3$ & Adj $R^{2}$ \\
\hline Ask & & & & \\
2-year & $1.09^{*}$ & $-0.62^{*}$ & $3.60^{*}$ & 0.64 \\
3-year & $1.09^{*}$ & $-0.15^{*}$ & $1.84^{*}$ & 0.58 \\
4-year & $1.08^{*}$ & $-0.06^{*}$ & $1.38^{*}$ & 0.62 \\
5-year & $1.11^{*}$ & 0.02 & $0.92^{*}$ & 0.57 \\
6-year & $1.11^{*}$ & $0.10^{*}$ & $0.50^{*}$ & 0.42 \\
7-year & $1.13^{*}$ & $0.19^{*}$ & $0.36^{*}$ & 0.25 \\
8-year & $1.08^{*}$ & $0.19^{*}$ & $0.11^{*}$ & 0.47 \\
9-year & $1.07^{*}$ & $0.18^{*}$ & $0.11^{*}$ & 0.51 \\
10-year & $1.13^{*}$ & $0.26^{*}$ & $0.07^{*}$ & 0.59 \\
Bid & & & & \\
2-year & $0.95^{*}$ & $-0.72^{*}$ & $2.40^{*}$ & 0.53 \\
3-year & $0.98^{*}$ & $-0.30^{*}$ & $0.87^{*}$ & 0.30 \\
4-year & $0.98^{*}$ & $-0.17^{*}$ & $0.69^{*}$ & 0.33 \\
5-year & $0.99^{*}$ & $-0.12^{*}$ & $0.55^{*}$ & 0.40 \\
6-year & $0.99^{*}$ & -0.01 & $0.36^{*}$ & 0.39 \\
7-year & $1.02^{*}$ & $0.11^{*}$ & $0.24^{*}$ & 0.52 \\
8-year & $0.98^{*}$ & $0.15^{*}$ & $0.07^{*}$ & 0.54 \\
9-year & $0.97^{*}$ & $0.14^{*}$ & $0.09^{*}$ & 0.59 \\
10-year & $1.03^{*}$ & $0.20^{*}$ & $0.06^{*}$ & 0.64 \\
\hline
\end{tabular}

This table presents regression results when the scaled implied flat volatility for euro interest rate caps and floors, for various maturities, is regressed on a quadratic function of the Log Moneyness Ratio (LMR), as follows:

Scaled IV $=c 1+c 2 * \mathrm{LMR}+c 3 * \mathrm{LMR}^{2}$

The statistics are presented for the period, Jan 99 - May 01, for various maturities, based on data obtained from WestLB Global Derivatives and Fixed Income Group. The coefficient and regression statistics are presented for caps and floors pooled together, separately for bid and ask prices, for all maturities. An asterisk implies significance at the $5 \%$ level. similar trends - the 2-year maturity contracts display a large curvature in the volatility smile, while the smile flattens out and turns into more of a skew as we move towards the longer maturity contracts, especially at the 10 -year maturity. More importantly, both the curvature and the slope of the volatility smile show significant time variation, sometimes even on a daily basis. The changes in the curvature and slope over time are more pronounced for the 2-year maturity contracts, although they are also perceptible for the longer maturity contracts. Fig. 2 also presents the surface plot of the euro spot interest rates for maturities from one to ten years, which also shows significant time variation in level and slope over our sample period.

Based on these figures, the natural question to ask is whether on a time-series basis, certain economic variables exhibit a significant relationship with the implied volatility smile patterns. In order to examine this question, we first need to define appropriate measures of the asymmetry and curvature of the smile curve each day. We can then determine empirical proxies for these attributes and estimate them using the volatility smile curve, each day. The measure of the asymmetry of the implied volatility curve, widely used by practitioners, is the "risk reversal," which is the difference in the implied volatility of the in-the-money and out-of-the-money options (roughly equally above and below the at-the-money strike rate). The measure of the curvature is the "butterfly spread," which is the difference between the average of the implied volatilities of two away-from-the-money volatilities and the at-the-money volatility. ${ }^{18}$ The advantage of using these empirical measures is that they explicitly capture the slope and the curvature of the smile curve. Therefore, they can be interpreted as proxies for the skewness and kurtosis of the risk-neutral distribution of interest rates.

We fit a quadratic function of the LMR to the scaled implied volatilities each day and use the fitted values to construct the risk reversal (RR) and butterfly spread (BS), defined as follows:

377

378

380

381

382

$$
\begin{aligned}
& \mathrm{RR}=\text { Scaled } \mathrm{IV}_{+0.25 \mathrm{LMR}}-\text { Scaled }_{\mathrm{IV}} \mathrm{IV}_{-0.25 \mathrm{LMR}} \\
& \mathrm{BS}=\left(\mathrm{Scaled}_{\mathrm{IV}} \mathrm{IV}_{+0.25 \mathrm{LMR}}+\mathrm{Scaled}_{\mathrm{IV}_{-0.25 \mathrm{LMR}}}\right) \\
& \not 2-\text { Scaled } \mathrm{IV}_{\mathrm{ATM}}
\end{aligned}
$$

The butterfly spread captures the average scaled implied volatility at 0.25 LMR away-from-the-money, on either side of 0 . It is essentially a linear transformation of the curvature coefficient from the quadratic function. Hence, it is our proxy for the curvature of the smile. The risk reversal represents the difference between the implied volatility of in-the-money options and out-of-the-money options. It is a linear transformation of the slope coefficient from the quadratic function. Thus, it is a proxy for the asymmetry in the slope of the smile. ${ }^{19}$

It is important to note that we estimate the risk reversal and the butterfly spread by only going away-fromthe-money by 0.25 LMR on either side of the at-themoney strike rate. To understand the moneyness levels in terms of actual contract strikes, consider a cap with an at-the-money strike rate of $4 \%$. In this case, a cap with an LMR of 0.25 would have a strike rate of about $3.1 \%$, while a cap with an LMR of -0.25 would have a strike rate of about $5.1 \%$. These strike rates are well within the range of actively traded caps in terms of moneyness.

\footnotetext{
18 These structures involve option-spread positions and are traded in the OTC interest rate and currency markets as explicit contracts. These prices are often used in the industry for calibrating interest rate option models. See, for example, Wystup (2003).

${ }^{19}$ Time-series plots of the risk reversal and the butterfly spread over our sample period show that both the slope and the curvature of the smile change almost on a daily basis, with the slope being more volatile than the curvature. The fluctuations in the slope of the smile are higher in the second half of our sample period, which is also one where interest rates increased. These variables could potentially be linked with each other through lead/lag relationships, which is one of the central issues that we examine in this paper. These plots have not been presented in the paper to conserve space, and are available from the authors.
} 

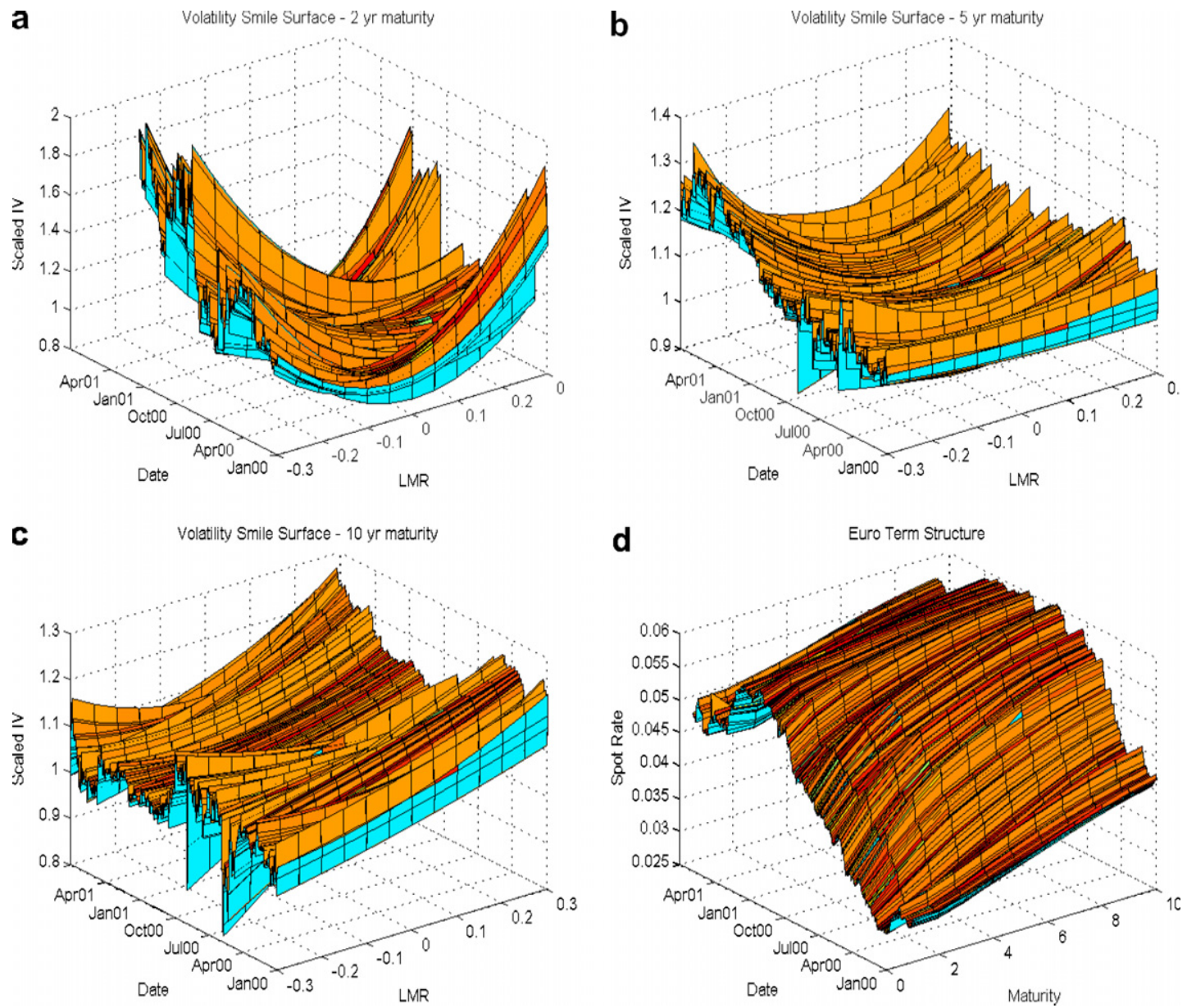

Fig. 2. Time variation in volatility smiles and the Euro term structure. This figure presents surface plots showing the time variation in the implied flat volatilities of euro interest rate caps and floors as well as the term structure of euro interest rates over the period Jan 99 - May 01. In figures a, b, and c, The horizontal axes correspond to the logarithm of the moneyness ratio, LMR, (defined as the ratio of the par swap rate to the strike rate of the option), and time. The vertical axis corresponds to the implied volatility of the mid-price (average of bid and ask price) of the option scaled by the at-the-money volatility for the option of similar maturity (Scaled IV). The values presented are the fitted values from a quadratic function of LMR as specified in Eq. (1) estimated every day. Figure $\mathrm{D}_{\Lambda}$ depicts the Euro spot rate surface by maturity (in years) over time (daily). The vertical axis corresponds to the spot rates. The horizontal axes correspond to the maturity of the spot rate and time, based on data obtained from WestLB Global Derivatives and Fixed Income Group.

\section{The determinants of the volatility smile}

One of the objectives of this paper is to examine the determinants of the volatility smiles in interest rate option markets. A clear understanding of the determinants of these smile patterns can help in developing models that eventually explain the entire smile. To this end, we explore the contemporaneous relationship between the slope and curvature of the daily smiles and several economic and liquidity variables. The economic determinants include the level of volatility of at-the-money interest rate options (ATMVol), the spot 6-month Euribor (6Mrate), the slope of the term structure captured by the difference between the 5-year rate and the 6 -month rate $(5 \mathrm{yr} 6 \mathrm{M}$ slope), the default spread defined as the 6-month Treasury-Euribor spread (DefSpread), and the scaled ATM bid-ask spreads (atmBAS) as a proxy of liquidity costs in the market. These are time-series regressions of curvature and asymmetry measures calculated using data across all the strikes each day. The regression specifications are as follows: ${ }^{20,21}$

$$
\begin{aligned}
\mathrm{BS}= & c 1+c 2 * \text { ATMVol }+c 3 * 6 \text { Mrate }+c 4 * 5 \mathrm{yr} 6 \text { Mslope } \\
& +c 5 * \text { DefSpread }+c 6 * \text { atmBAS } \\
\mathrm{RR}= & d 1+d 2 * \text { ATMVol }+d 3 * 6 \text { Mrate } \\
& +d 4 * 5 \mathrm{yr} 6 \mathrm{Mslope}+d 5 * \text { DefSpread }+d 6 * \text { atmBAS. }
\end{aligned}
$$

${ }^{20}$ This time-series regression is estimated by including AR(2) error terms to correct for serial correlation. We find no serial correlation in the residuals after this correction. In addition, for all maturities, the DurbinWatson statistic is insignificantly different from 2 . Therefore, the inclusion of the $\operatorname{AR}(2)$ error terms, indeed, takes care of any serial correlation in the regression model.

${ }^{21}$ We also estimate this equation using the slope and curvature of the smile obtained from unscaled (absolute) implied volatilities, as well as using volatility and maturity adjusted moneyness (in the spirit of $\mathrm{Li}$ and Pearson (2004)). The results, which are similar, are not reported in the paper to save space, but are available upon request from the authors. 
The intuition for examining these independent variables is as follows. First, the at-the-money volatility variable is added to examine whether the patterns of the smile vary significantly with the level of uncertainty in the market. During more uncertain times, reflected by higher volatility, market makers may charge higher than normal asking prices for away-from-the-money options, since they may be more averse to taking short position at these strike rates. This would lead to a steeper smile, especially on the askside of the smile curve. Also, during times of greater uncertainty, a risk-averse market maker may demand higher compensation for providing liquidity to the market, which would affect the shape of the smile. Since we have already divided the volatility of each option by the volatility of the corresponding ATM cap to obtain the scaled IV, we use the ATM swaption volatility (of comparable maturity), a general measure of the future interest rate volatility, as an explanatory variable here, in order to avoid having the same variable on both sides of the regression equation. ${ }^{22}$

Second, we include the spot 6-month Euribor and the slope of the yield curve as indicators of general economic conditions, as well as the direction of interest rate changes in the future - for example, if interest rates are meanreverting, very low interest rates are likely to be followed by rate increases. Similarly, an upward-sloping yield curve is also indicative of future rate increases. This would manifest itself in a higher demand for out-of-the-money caps in the market, thus affecting the prices of these options, and possibly the shape of the implied volatility smile itself. ${ }^{23}$

Our next variable, the default spread, is often used as a measure of aggregate liquidity as well as the default risk of the constituent banks in the Euribor fixing. A wider spread indicates a higher default risk for the constituent banks, and possibly also higher risk of default of interest rate option dealers. It could affect the prices of away-fromthe-money options more than the prices of ATM options, thus affecting the shape of the smile.

We also include a measure of the at-the-money relative bid-ask spreads of these options. The objective of including this variable is to directly control for the explicit liquidity of these options, while examining the relationship of the other economic variables to the volatility smile. The relative bid-ask spreads of ATM options capture the general level of liquidity in the market.

The results from this regression analysis are presented in Table 2 . The curvature of the smile is positively and significantly related to the 6-month interest rate, with the effect being insignificant for long maturity options. When interest

\footnotetext{
${ }^{22}$ Although swaption implied volatilities are not exactly the same as the cap/floor implied volatility, they both tend to move together. Hence, swaption implied volatilities are a valid proxy for the perceived uncertainty in the future interest rates. The data on the ATM swaption volatility in the Euro market was obtained from DataStream.

${ }^{23}$ The ATM volatility and the term structure variables act as approximate controls for a model of interest rates that displays skewness and excess kurtosis. Typically, in such models the future distribution of interest rates depends on today's volatility and the level of interest rates.
}

rates are high, the away-from-the-money options, especially the ones with shorter maturities, are priced relatively higher than during times when interest rates are low. On the other hand, the curvature of the smile is negatively related to the slope of the term structure; interestingly, this effect is significant only for the longer maturity options. It appears that the volatility smiles in this market have more curvature when the term structure is relatively flat. These results are consistent for the bid- as well as the ask-side quotations.

The results also show that the degree of curvature is negatively related to the volatility of at-the-money options, although this effect is significant mostly for short/medium maturity options. Therefore, highly volatile periods tend to be associated with a lower curvature of the smile, which is consistent with the evidence in the equity options literature (Pena et al., 1999). These results suggest a stochastic volatility framework with the volatility itself exhibiting mean reversion. In such a model, high-volatility periods are likely to be followed by lower volatility periods, which would result in a shallow smile when volatility is high. We also find weak evidence of the curvature of the smile being positively related to the liquidity costs in the market, but this effect is significant only for long maturity options on the ask-side. This is understandable, since higher liquidity costs i.e. higher costs of continuously hedging the options positions would of more concern in case of away from the money options and longer maturities. Therefore, especially for longer maturity options, it may be important to account for liquidity effects while modeling the volatility smile.

The slope of the volatility smile (RR) exhibits somewhat different relationships to the contemporaneous determinants examined in this section. When the short-term interest rate is high, the RR appears to be more negative, especially for longer maturity options. Since the RR is the difference between Scaled IVs at +0.25 LMR and $-0.25 \mathrm{LMR}$, it is important to understand the effects separately for caps and floors. A negative (positive) LMR refers to out-of-the-money caps (floors). A negative relationship between 6-month rate and RR implies that when interest rates increase (decrease), out-of-the-money caps (floors) become disproportionately expensive. These results are quite intuitive. It is possible that the demand for out-ofthe-money caps (floors) is higher when interest rates go up (down). Then, consistent with the findings of Bollen and Whaley (2004) and Garleanu et al. (2006), demand pressure may affect the prices of interest rate options at some strikes, thereby affecting the shape of the volatility smile. Similarly, when the term structure becomes more steeply upward sloping, the smile becomes more negative. An upward-sloping yield curve is a signal that interest rates will increase in the future, thereby leading to higher demand for out-of-the-money caps, which would make the volatility smile more negative. An alternate way of thinking about this effect is that the slope of the yield curve captures the skew of the distribution of future interest rates, thus affecting the slope of the smile. 
Table 2

Effects of economic variables on volatility smiles

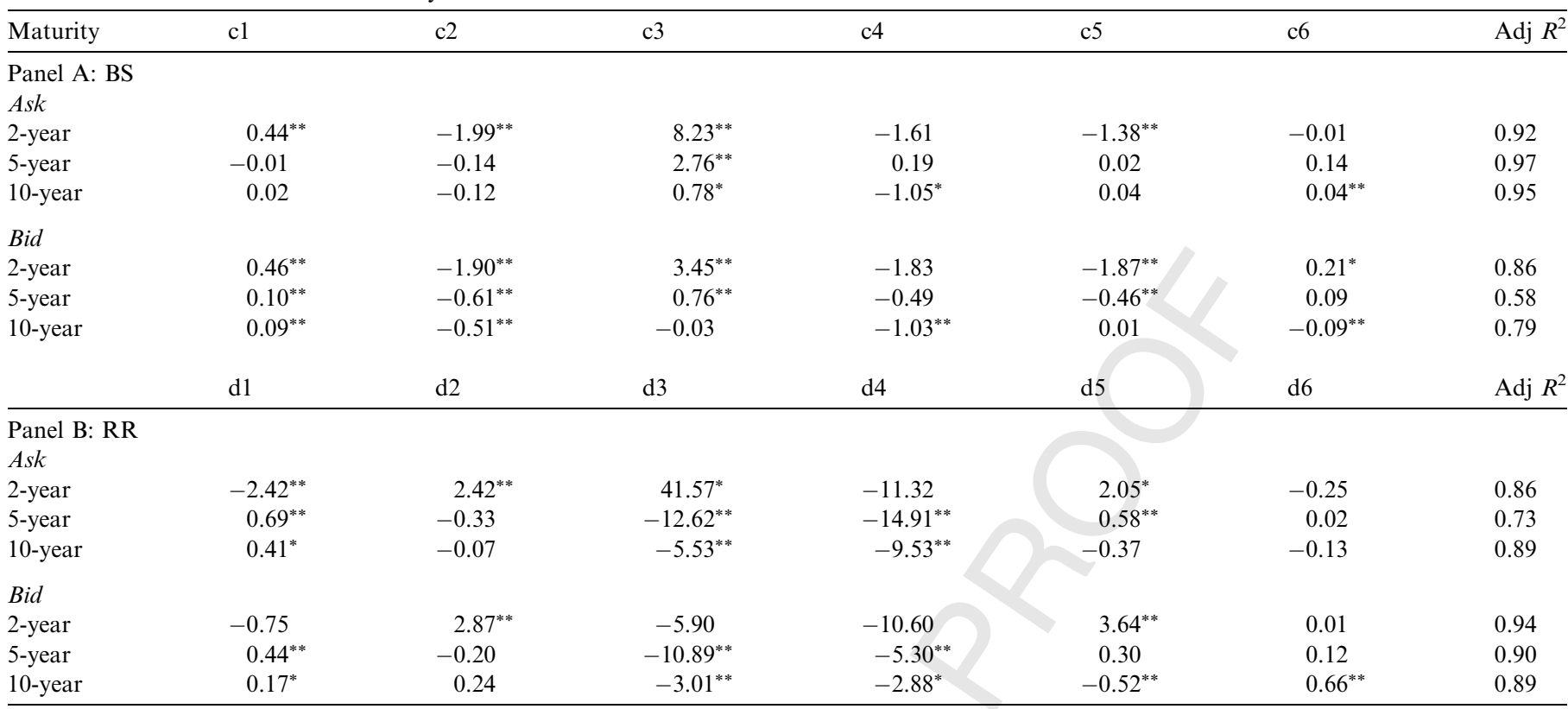

This table presents regression results for the impact of economic and liquidity variables on the curvature of the volatility smile (as proxied by the butterfly spread, BS) and asymmetry in the volatility smile (as proxied by risk reversal, RR):

$\mathrm{BS}=c 1+c 2 * \mathrm{ATMVol}+c 3 * 6$ Mrate $+c 4 * 5 \mathrm{yr} 6$ Mslope $+c 5 *$ DefSpread $+c 6 *$ atmBAS

$\mathrm{RR}=d 1+d 2 * \mathrm{ATMVol}+d 3 * 6$ Mrate $+d 4 * 5 \mathrm{yr} 6 \mathrm{Mslope}+d 5 *$ DefSpread $+d 6 *$ atmBAS

Finally, we find some evidence that the slope of the smile curve is related to the default spread. However, this relationship is not consistent across all maturities. Perhaps there is a relation between RR and the leads or lags of the default spread. The nature of such dynamic relationships between the economic variables and the volatility smile is what we explore in the next section.

\section{Multivariate vector autoregression}

In the previous section, we show that economic variables are significantly related to the shape of the contemporaneous smile. In this section, we examine the relationship between the lagged values of economic variables and the shape of the smile, and vice versa. We estimate a six-equation, multivariate, vector autoregression separately for the butterfly spread and the risk reversal, each of which includes the five economic and liquidity variables (ATM volatility, 6-month rate, the slope of the term structure, the default spread, and the ATM bid-ask spreads). ${ }^{24}$ This framework can provide useful information on the linkages between the economic variables and the volatility smile in a

\footnotetext{
${ }^{24}$ We thank Rob Engle for insightful discussions on the econometric procedures used in this section.
}

dynamic, predictive sense. We choose the appropriate number of lags for the multivariate VAR estimation in each case, using the Akaike information criterion (AIC). For most option maturities, this estimation results in two or three lags, with the maximum number of lags in any system being five. We estimate 36 VAR models ( 9 option maturities each, for the bid and ask sides, separately for BS and RR) that provide a comprehensive description of the time-series movements in the shape of the smile and the economic and liquidity variables.

We first examine the cross-correlations of the innovations obtained from the VAR system. Unexpected shocks to any of the economic variables may be related to the unexpected fluctuations in the shape of the volatility smile. These correlations are presented in Table 3 . The most striking relationship noticed from the table is the negative correlation between the shocks to the slope of the term structure and the shocks to the curvature and slope of the volatility smile, which is consistent with our results in the previous section. It appears that unexpected twists in the term structure, which may be proxies for unexpected changes in the higher moments of the risk-neutral distribution of interest rates, are related to unexpected changes in the shape of the volatility smile curve. To a lesser degree, we find that the shocks to the 6-month interest rate are pos- 
Table 3

Correlations in VAR innovations

\begin{tabular}{|c|c|c|c|c|c|c|c|c|c|c|}
\hline & \multicolumn{5}{|l|}{ Ask } & \multicolumn{5}{|l|}{ Bid } \\
\hline & ATM vol. & $\begin{array}{l}6 \mathrm{~m} \\
\text { Rate }\end{array}$ & $\begin{array}{l}5 \text { years rate }-6 \mathrm{~m} \\
\text { Rate }\end{array}$ & $\begin{array}{l}\text { Default } \\
\text { Spread }\end{array}$ & $\begin{array}{l}\text { ATM BA } \\
\text { Spread }\end{array}$ & $\begin{array}{l}\text { ATM } \\
\text { vol. }\end{array}$ & $\begin{array}{l}6 \mathrm{~m} \\
\text { Rate }\end{array}$ & $\begin{array}{l}5 \text { years rate }-6 \mathrm{~m} \\
\text { Rate }\end{array}$ & $\begin{array}{l}\text { Default } \\
\text { Spread }\end{array}$ & $\begin{array}{l}\text { ATM BA } \\
\text { Spread }\end{array}$ \\
\hline \multicolumn{11}{|l|}{$B S$} \\
\hline 5-year & -0.06 & $0.15^{* *}$ & -0.01 & 0.04 & $0.16^{* *}$ & -0.07 & -0.04 & $0.10^{* *}$ & $-0.10^{* *}$ & 0.02 \\
\hline 10 -year & -0.05 & $0.14^{* *}$ & $-0.14^{* *}$ & $0.08^{*}$ & $0.13^{* *}$ & $-0.10^{* *}$ & $0.12^{* *}$ & -0.08 & 0.07 & $-0.15^{* *}$ \\
\hline 5-year & -0.02 & -0.04 & $-0.46^{* *}$ & $0.13^{* *}$ & 0.06 & 0.00 & $-0.09^{* *}$ & $-0.21^{* *}$ & 0.05 & 0.04 \\
\hline 10 -year & 0.04 & $-0.13^{* *}$ & $-0.14^{* *}$ & $-0.09^{*}$ & -0.07 & $0.08^{*}$ & -0.07 & -0.03 & $-0.16^{* *}$ & $0.15^{* *}$ \\
\hline
\end{tabular}

This table presents the correlations between innovations from the multivariate vector autoregression for six variables - the level of volatility of at-themoney interest rate options (ATM vol.), the spot 6-month Euribor (6 m rate), the slope of the term structure $(5$ years rate $-6 \mathrm{~m}$ rate), the 6-month Treasury-Euribor spread (Default Spread), the scaled ATM bid-ask spreads (ATM BA spread) and butterfly spread (BS) or risk reversal (RR) separately for ask and bid sides for the period Jan 99 - May 01, based on data obtained from WestLB Global Derivatives and Fixed Income Group and DataStream. The correlations between innovations of the smile variables $(\mathrm{BS} / \mathrm{RR})$ and innovations and other variables are presented below ${ }^{* *}$ and ${ }^{*}$ represent $p$-values less than or equal to $5 \%$ and $10 \%$, respectively. The results are presented for three representative maturities -2 -year, 5 -year, and 10 -year.

itively correlated with the shocks to the shape of the smile, especially to the butterfly spread. An unexpected increase in interest rates may trigger expectations of extreme moves in interest rates in the future, which would cause the butterfly spread to increase. Similarly, we find some relationship between shocks to the default spread and shocks to the shape of the volatility smile. In addition, the shocks to the liquidity of at-the-money options appear to be positively related to the shocks to the butterfly spread, especially for longer maturities. This suggests that when liquidity dries up, the away-from-the-money options (especially longer maturity) become disproportionately more expensive, as reflected in the increase in the curvature of the smile.

\subsection{The predictors of the volatility smile}

In Table 4, we present the pair-wise Granger-causality tests between the butterfly spread or risk reversal and the five economic variables, separately for the bid- and askside, for each maturity. Panel A of the table presents the $p$-values for rejecting the null hypothesis that variable $i$ Granger-causes the shape of the smile (butterfly spread or risk reversal), by testing whether the lag coefficients of variable $i$ are jointly zero when the dependent variable in the VAR is BS or RR. We find evidence that for most option maturities, the 6-month interest rate and the slope of the term structure Granger-cause the butterfly spread. Therefore, these yield curve variables have an impact not only on the contemporaneous BS, as seen from Tables $3_{\lambda}$ and $4_{k}$ but also on the future BS. Similarly, we find some evidence that the 6-month interest rate Granger-causes the risk reversal. Thus, while the slope of the yield curve is related to contemporaneous $\mathrm{RR}$, it is the spot rate that has predictive information about future values of RR. These results show that past realizations of the term structure have some information about the shape of the volatil- ity smiles in this market. We also find some information in past values of the at-the-money volatility and liquidity costs in predicting the curvature of the volatility smile, but these effects are weaker.

Next, we present the impulse responses based on the multivariate VAR standardized by Cholesky decomposition. For the sake of brevity, we only show those cases where we do find Granger-causality. Panel A of Fig. 3 presents the response of the butterfly spread to a one Cholesky standard deviation shock to the 6 month rate. The ordering of the VAR for this purpose is the 6-month rate, the 5 years rate $-6 \mathrm{~m}$ rate differential, the default spread, the ATM BA Spread, BS, and ATM vol. ${ }^{25}$ On the ask-side, except for the 2-year cap, a positive shock to the short-term interest rate results in an increase in the butterfly spread. The effect is significant initially, and remains so for 5-year and shorter maturities. For longer maturities, the effect becomes insignificant as the horizon progresses. On the bid-side the results are qualitatively similar. ${ }^{26}$

Panel B of Fig. 3 shows the response of the risk reversal to one Cholesky standard deviation shock to the 6 month interest rate. The ordering of the VAR in this case is the 6-month rate, the $\mathrm{RR}$, the 5 years rate $-6 \mathrm{~m}$ rate differential, the default spread, the ATM vol, and the ATM BA Spread. On the ask-side, except for the short-term maturities like the 2-year, there is a decrease in the risk reversal following a positive shock to the short-term interest rate.

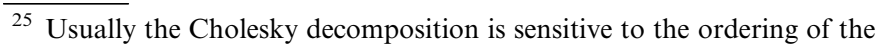
VAR. We order the VAR from the most exogenous variable to the most endogenous variable, based on the results of Granger-causality tests. However, our empirical results are robust to changes in the ordering of these variables in the VAR.

${ }^{26}$ We also examined the response of the butterfly spread to the slope of the yield curve computed in the manner explained above. Although Granger-causality points to the slope of the yield curve having information about the butterfly spread, the impulse responses do not show a clear pattern.
} 
Table 4

Granger-causality tests

\begin{tabular}{|c|c|c|c|c|c|c|c|c|c|}
\hline \multicolumn{5}{|l|}{ Ask } & \multicolumn{5}{|l|}{ Bid } \\
\hline $\begin{array}{l}\text { ATM } \\
\text { vol. }\end{array}$ & $\begin{array}{l}6 \mathrm{~m} \\
\text { Rate }\end{array}$ & $\begin{array}{l}5 \text { years rate }-6 \mathrm{~m} \\
\text { Rate }\end{array}$ & $\begin{array}{l}\text { Default } \\
\text { spread }\end{array}$ & $\begin{array}{l}\text { ATM BA } \\
\text { spread }\end{array}$ & $\begin{array}{l}\text { ATM } \\
\text { vol. }\end{array}$ & $\begin{array}{l}6 \mathrm{~m} \\
\text { Rate }\end{array}$ & $\begin{array}{l}5 \text { years rate }-6 \mathrm{~m} \\
\text { Rate }\end{array}$ & $\begin{array}{l}\text { Default } \\
\text { spread }\end{array}$ & $\begin{array}{l}\text { ATM BA } \\
\text { spread }\end{array}$ \\
\hline
\end{tabular}

Panel A: Null Hypothesis - presented variables do not individually Granger-cause the butterfly spread (BS)/risk reversal (RR) on the ask/bid side BS

\begin{tabular}{|c|c|c|c|c|c|c|c|c|c|c|}
\hline 2-year & 0.61 & $0.05^{* *}$ & 0.98 & 0.73 & 0.65 & 0.43 & $0.05^{* *}$ & $0.09^{*}$ & 0.44 & 0.97 \\
\hline 5 -year & $0.01^{* *}$ & $0.00^{* *}$ & $0.00^{* *}$ & 0.57 & $0.04^{* *}$ & 0.38 & 0.22 & $0.06^{*}$ & $0.07^{*}$ & 0.74 \\
\hline 10 -year & 0.29 & 0.33 & 0.12 & $0.04^{* *}$ & 0.71 & $0.00^{* *}$ & 0.70 & $0.00^{* *}$ & 0.40 & 0.75 \\
\hline \multicolumn{11}{|l|}{$R R$} \\
\hline 2-year & 0.58 & 0.92 & 0.74 & 0.81 & 0.16 & 0.89 & 0.18 & 0.81 & 0.46 & 0.11 \\
\hline 5-year & $0.00^{* *}$ & $0.00^{* *}$ & 0.30 & 0.47 & 0.22 & 0.26 & $0.00^{* *}$ & $0.00^{* *}$ & $0.06^{*}$ & 0.73 \\
\hline 10 -year & $0.01^{* *}$ & $0.09^{*}$ & $0.00^{* *}$ & 0.69 & 0.42 & 0.85 & 0.13 & $0.00^{* *}$ & 0.50 & $0.00^{*}$ \\
\hline
\end{tabular}

Panel B: Null Hypothesis - Butterfly spread (BS)/risk reversal (RR) on the ask/bid side do not Granger-cause each of the presented variables BS

\begin{tabular}{lllllllllll} 
2-year & 0.58 & 0.28 & 0.69 & 0.15 & 0.80 & 0.92 & 0.12 & 0.34 & 0.27 & 0.72 \\
5-year & 0.58 & 0.28 & $0.01^{* *}$ & 0.16 & 0.60 & 0.95 & 0.47 & 0.81 & 0.72 & 0.60 \\
10-year & $0.00^{* *}$ & 0.77 & 0.92 & $0.01^{* *}$ & 0.21 & 0.31 & 0.15 & 0.38 & \\
$R R$ & & & & & & & & & & \\
2-year & 0.83 & 0.78 & 0.45 & 0.47 & 0.33 & 0.39 & 0.56 & 0.79 & $0.00^{* *}$ \\
5-year & 0.14 & 0.39 & $0.02^{* *}$ & 0.28 & $0.00^{* *}$ & 0.67 & $0.04^{* *}$ & 0.19 & 0.13 \\
10-year & 0.81 & 0.22 & 0.16 & $0.00^{* *}$ & $0.00^{* *}$ & 0.19 & 0.97 & 0.37 & 0.10 & $0.08^{*}$ \\
\hline
\end{tabular}

This table presents results for the Granger-causality tests based on the multivariate vector autoregression for six variables - the level of volatility of at-themoney interest rate options (ATM vol.), the spot 6-month Euribor $(6 \mathrm{~m}$ rate), the slope of the term structure $(5$ years rate $-6 \mathrm{~m}$ rate), the 6 -month Treasury-Euribor spread (Default spread), the scaled ATM bid-ask spreads (ATM BA spread) and butterfly spread (BS) or risk reversal (RR) separately for ask and bid sides for the period Jan 99 - May 01, based on data obtained from WestLB Global Derivatives and Fixed Income Group and DataStream. The $p$-values for rejecting the null hypothesis of "No Granger-Causality" are given below. ** and * represent $p$-values less than or equal to $5 \%$ and $10 \%$, respectively. The results are presented for three representative maturities - 2-year, 5-year, and 10-year.

The results are consistent with the intuition that an increase in the short-term interest rate is followed by an increase in the prices of the out-of-the-money caps, since investors are now more concerned about hedging the risk of rising interest rates. Hence, the prices of out-the-money caps $(\mathrm{LMR}<0)$ relative to in-the-money caps $(\mathrm{LMR}>0)$ increase, thereby decreasing the risk reversal. An alternate way of thinking about this result is that investors are less concerned about hedging the risk of decreasing interest rates. Therefore, the prices of out-of-the-money floors $(\mathrm{LMR}>0)$ relative to in-the-money floors $(\mathrm{LMR}<0)$ decrease. The results on the bid-side are similar.

Table 5 presents the variance decompositions of the butterfly spread and risk reversal. It shows how much each of the variables contributes towards the variance of the error in forecasting the shape of the smile. The bulk of the variance of the forecast error in the butterfly spread or risk reversal is attributable to the innovations in that variable itself. For butterfly spreads at shorter maturity, the 6month interest rate contributes around 2\% towards the forecast error variance at the horizon of one day. This contribution increases to around $6 \%$ at the 10-day horizon. The contributions are smaller for higher maturities. Atthe-money volatility is another variable that contributes towards the forecast error variance of butterfly spread. For the risk reversal as well, innovations to the 6-month rate are the next contributing factor, after innovations to the risk reversal itself. Excluding the 2-year maturity, the contribution of innovations to the short rate starts at around $1 \%$ at a 1 -day horizon and goes up to $4-5 \%$ at the 10-day horizon.

\subsection{Information in the volatility smile}

Panel B of Table 4 presents $p$-values for the null hypothesis that the shape of the smile (measured by the BS or RR) does not Granger-cause any of the other variables of interest. We find that the shape of the volatility smile plays a role in predicting some of the economic variables. In particular, the risk reversal Granger-causes the 6-month default spread, implying that the asymmetry in the volatility smile curves is useful for predicting the default spread in the Euribor market. This is intuitive since the option prices are forward looking. More importantly, our results suggest that the asymmetry in the prices of out-the-money options as compared to those for in-the-money options (which is the cause of the asymmetry in the volatility smile) have information about the future economic outlook, since the default spread is a reflection of the expectations for aggregate default risk in the economy.

Panel $\mathrm{C}$ of Fig. 3 presents the response of the default spread to a one Cholesky standard deviation shock to risk reversal computed in a manner similar to earlier responses. The ordering of the VAR in this case is 6 -month rate, $R R$, the 5 years rate $-6 \mathrm{~m}$ rate spread, the default spread, the ATM vol, and the ATM BA Spread. A positive shock to 
Panel A: Response of the butterfly spread to the 6-month interest rate
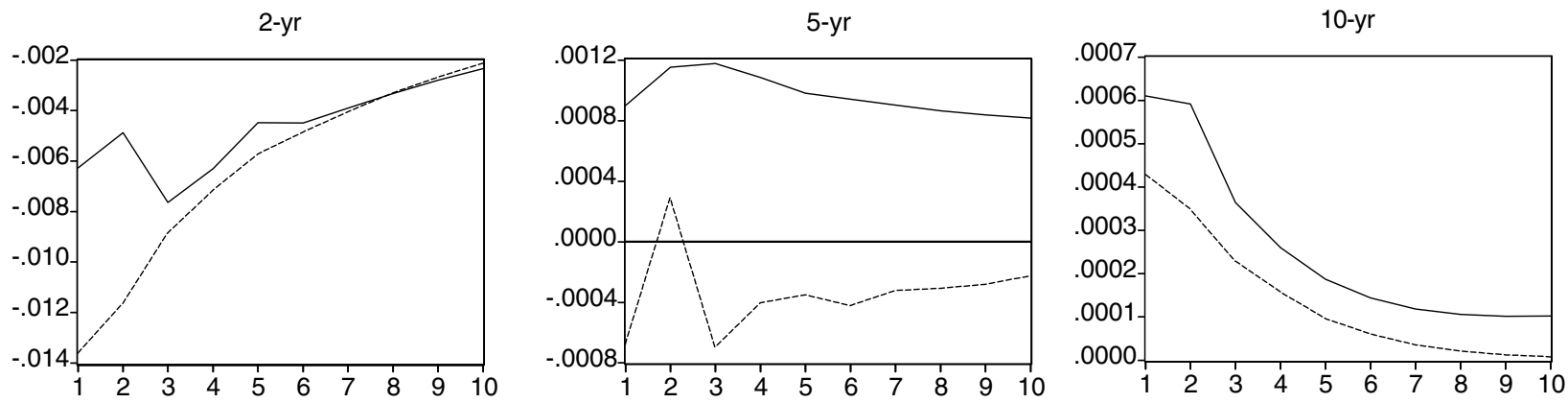

Panel B: Response of the risk reversal to the 6-month interest rate
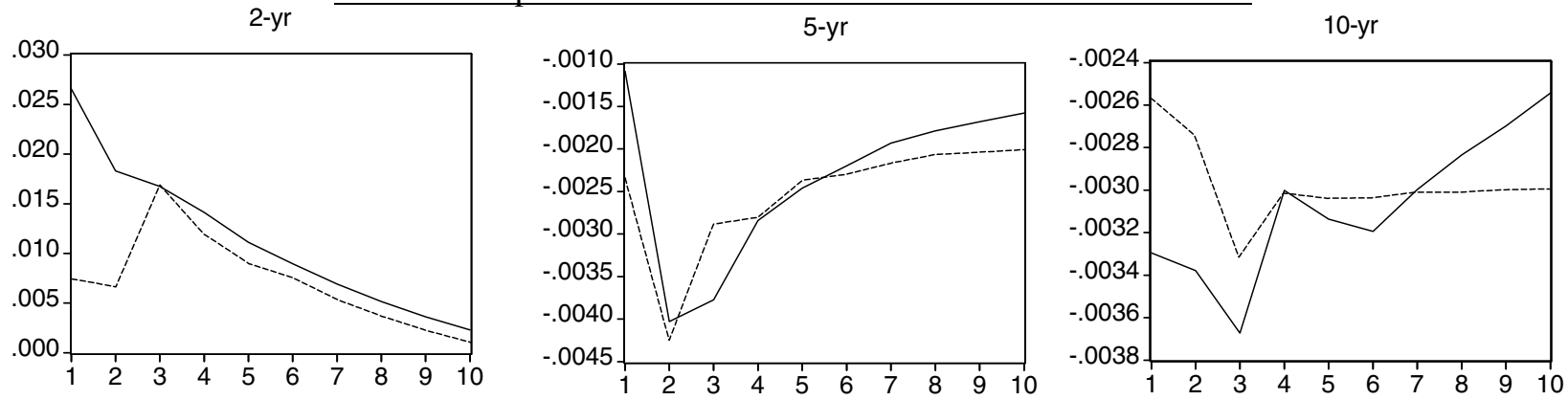

Panel C: Response of the default spread to the risk reversal

$2-\mathrm{yr}$

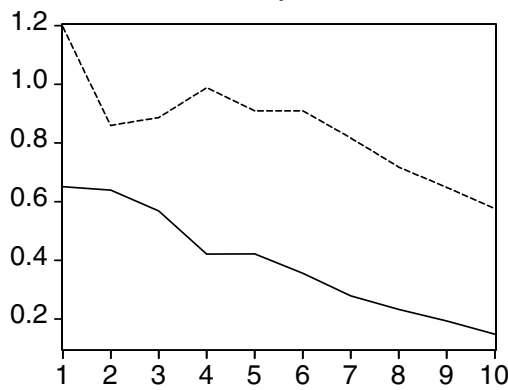

$5-y r$

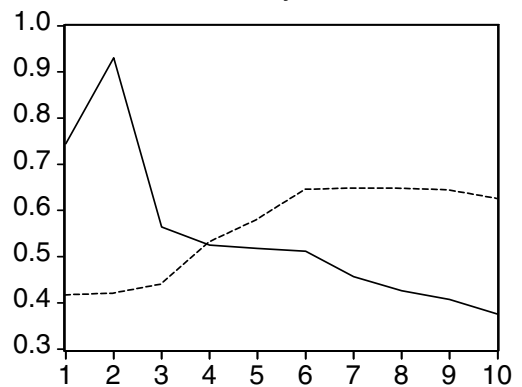

$10-\mathrm{yr}$

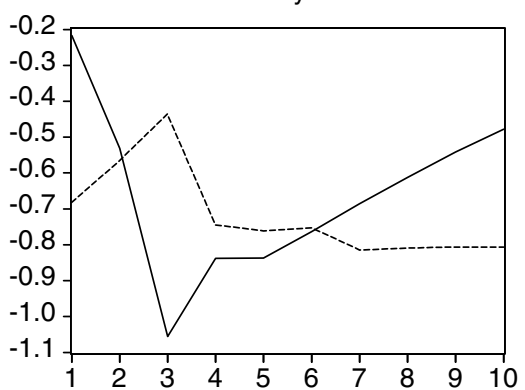

Fig. 3. Impulse responses. This figure presents impulse responses computed from the multivariate vector autoregression for six variables - the level of volatility of at-the-money interest rate options (ATM vol.), the spot 6-month Euribor (6 m rate), the slope of the term structure (5 years rate - $6 \mathrm{~m}$ rate), the 6-month Treasury-Euribor spread (Default spread), the scaled ATM bid-ask spreads (ATM BA spread) and butterfly spread (BS) or risk reversal (RR) separately for ask and bid sides for the period Jan 99 - May 01, based on data obtained from WestLB Global Derivatives and Fixed Income Group and DataStream. The figure shows response for three representative maturities - 2-year, 5-year, and 10-year. VARs are ordered as follows: for BS $6 \mathrm{~m}$ Rate, 5 years rate $-6 \mathrm{~m}$ Rate, Default Spread, ATM BA spread, BS, and ATM vol. and for RR $6 \mathrm{~m}$ Rate, RR, 5 years rate - $6 \mathrm{~m}$ Rate, Default Spread, ATM vol., and ATM BA spread. The solid line represents the ask side while the dashed line represents the bid side. Panel A: Response of the butterfly spread to the 6month interest rate; Panel B: Response of the risk reversal to the 6-month interest rate; Panel C: Response of the default spread to the risk reversal.

the risk reversal for shorter maturities (up to 6-year) is followed by a significant increase in the default spread. The results are insignificant for higher maturities. The results are consistent with a positive correlation, at short maturities, between unexpected shocks to risk reversal and default spread. An increase in the risk reversal occurs during the period when investors are more concerned about falling interest rates (leading to enhanced interest in buying outof-the-money floors), which usually coincides with an economic downturn and a consequent increase in default risk.

Panel $\mathrm{C}$ of Table 5 presents the decomposition of the forecast error variance of default spread computed from the VAR involving risk reversal. Similar to previous cases, own innovations contribute the most towards forecast error variance of default spread. However, it is interesting to note that shocks to the risk reversal contribute up to $8 \%$ to the variance of the forecast error. This is a result consistent with what we find using Granger-causality: risk reversal has information about the default spread.

\section{Concluding remarks}

We examine the patterns of implied volatility in the euro interest rate option markets, using data on bid and ask prices of interest rate caps and floors across strike rates. We document the pattern of implied volatility across strike 
Table 5

Variance decomposition

\begin{tabular}{|c|c|c|c|c|c|c|c|c|c|c|c|c|c|c|c|}
\hline \multirow[t]{2}{*}{ Maturity } & \multirow{2}{*}{$\begin{array}{l}\text { Forecast } \\
\text { Horizon (Days) }\end{array}$} & \multicolumn{7}{|c|}{ Ask } & \multicolumn{7}{|l|}{ Bid } \\
\hline & & $\begin{array}{l}\text { Forecast } \\
\text { standard error }\end{array}$ & $\begin{array}{l}\text { ATM } \\
\text { vol. }\end{array}$ & $\begin{array}{l}6 \mathrm{~m} \\
\text { Rate }\end{array}$ & $\begin{array}{l}5 \text { years rate - } \\
6 \mathrm{~m} \text { Rate }\end{array}$ & $\begin{array}{l}\text { Default } \\
\text { spread }\end{array}$ & $\begin{array}{l}\text { ATM BA } \\
\text { spread }\end{array}$ & $\overline{\mathrm{BS} / \mathrm{RR}}$ & $\begin{array}{l}\text { Forecast } \\
\text { standard } \\
\text { error }\end{array}$ & $\begin{array}{l}\text { ATM } \\
\text { vol. }\end{array}$ & $\begin{array}{l}6 \mathrm{~m} \\
\text { Rate }\end{array}$ & $\begin{array}{l}5 \text { years rate }- \\
6 \mathrm{~m} \text { rate }\end{array}$ & $\begin{array}{l}\text { Default } \\
\text { spread }\end{array}$ & $\begin{array}{l}\text { ATM BA } \\
\text { spread }\end{array}$ & $\overline{B S / R R}$ \\
\hline \multicolumn{16}{|c|}{ Panel A: Variance decomposition of butterfly spread } \\
\hline \multirow[t]{2}{*}{ 2-year } & 1 & 0.4 & 0.0 & 2.1 & 0.0 & 0.7 & 0.0 & 97.2 & 0.4 & 0.0 & 8.2 & 0.0 & 1.2 & 0.3 & 90.3 \\
\hline & 10 & 1.1 & 1.7 & 4.4 & 0.1 & 0.3 & 0.2 & 93.3 & 1.1 & 1.2 & 11.8 & 6.2 & 3.9 & 0.2 & 76.7 \\
\hline \multirow[t]{2}{*}{ 5-year } & 1 & 0.2 & 0.0 & 2.8 & 0.0 & 0.0 & 2.2 & 95.5 & 0.2 & 0.0 & 0.2 & 0.9 & 0.8 & 0.3 & 97.9 \\
\hline & 10 & 0.6 & 3.5 & 7.6 & 3.0 & 2.3 & 1.9 & 81.8 & 0.6 & 0.7 & 0.5 & 1.2 & 5.5 & 0.4 & 91.7 \\
\hline \multirow[t]{2}{*}{ 10-year } & 1 & 0.1 & 0.0 & 2.0 & 0.9 & 0.1 & 1.6 & 95.4 & 0.1 & 0.0 & 1.5 & 0.1 & 0.1 & 2.2 & 96.1 \\
\hline & 10 & 0.3 & 4.5 & 1.1 & 0.2 & 5.6 & 0.8 & 87.8 & 0.4 & 11.9 & 1.5 & 1.1 & 0.4 & 2.2 & 82.9 \\
\hline \multicolumn{16}{|c|}{ Panel B: Variance decomposition of risk reversal } \\
\hline \multirow{2}{*}{2 -year } & 1 & 0.4 & 0.0 & 6.8 & 0.0 & 0.0 & 0.0 & 93.2 & 0.4 & 0.0 & 0.6 & 0.0 & 0.0 & 0.0 & 99.4 \\
\hline & 10 & 1.2 & 0.0 & 6.3 & 0.3 & 0.5 & 4.0 & 88.9 & 1.1 & 0.0 & 3.3 & 0.3 & 0.9 & 4.0 & 91.4 \\
\hline \multirow[t]{2}{*}{5 -year } & 1 & 0.2 & 0.0 & 0.2 & 0.0 & 0.0 & 0.0 & 99.8 & 0.2 & 0.0 & 0.9 & 0.0 & 0.0 & 0.0 & 99.1 \\
\hline & 10 & 0.6 & 2.3 & 5.8 & 0.6 & 0.5 & 1.1 & 89.7 & 0.6 & 1.0 & 5.9 & 1.7 & 3.2 & 0.1 & 88.2 \\
\hline \multirow[t]{2}{*}{ 10-year } & 1 & 0.2 & 0.0 & 1.6 & 0.0 & 0.0 & 0.0 & 98.4 & 0.7 & 0.0 & 0.5 & 0.0 & 0.0 & 0.0 & 99.5 \\
\hline & 10 & 0.4 & 2.5 & 3.3 & 2.6 & 0.4 & 1.7 & 89.5 & 0.4 & 0.6 & 3.4 & 1.5 & 0.1 & 8.2 & 86.2 \\
\hline
\end{tabular}

Panel C: Variance decomposition of default spread

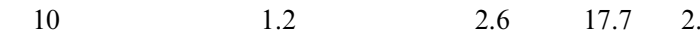

5-year $\quad 1-0.2-0.0-12.4 \quad 0.3$

$\begin{array}{ll}12.4 & 0.3 \\ 19.7 & 0.8\end{array}$

$\begin{array}{rrrrrr}10 \text {-year } & 1 & 0.2 & 0.0 & 12.6 & 0.0 \\ & 10 & 0.4 & 0.3 & 17.5 & 0.5\end{array}$

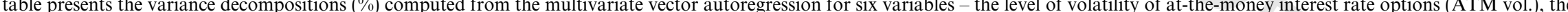
spot 6-month Euribor ( $6 \mathrm{~m}$ rate), the slope of the term structure ( 5 years rate $-6 \mathrm{~m}$ rate), the 6-month Treasury-Euribor spread (Default spread), the scaled ATM bid-ask spreads (ATM BA spread) and butterfly spread (BS) or risk reversal (RR) separately for ask and bid sides for the period Jan 99 - May 01, based on data obtained from WestLB Global Derivatives and Fixed Income Group and

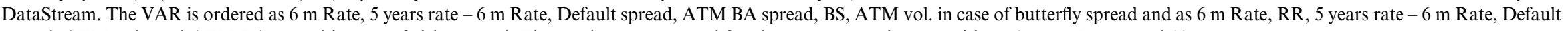
spread, ATM vol., and ATM BA spread in case of risk reversal. The results are presented for three representative maturities - 2-year, 5-year, and 10-year. 
rates for these options, separately on the bid-side and the ask-side, and find that the volatility smile curve is clearly evident in this market.

We further examine the impact of economic variables on the volatility smile curves. We include the level of volatility and interest rates to control for the effects arising out of a more elaborate model of interest rates. We find that these term structure variables have significant explanatory ability for the time variation in the shape of the smile. During a high-interest rate regime, the smile appears to be steeper and more skewed. When the yield curve is sloping upward more steeply, the smile in the interest rate options is flatter but more skewed. In addition, when the level of volatility in the interest rate markets is high, the smile is flatter, consistent with mean-reverting stochastic volatility.

We investigate the behavior of the relationship between the yield curve variables and the shape of the smile over time and find that it is not static but dynamic. The yield curve variables have information about the future shape of the smile in the interest rate options market. Thus, past values of yield curve variables can be used to formulate and implement hedging and risk management strategies for the interest rate options. We also find that the shape of the smile has information about future default spreads. Thus, past prices of interest rate options can be useful for valuing and hedging credit derivatives. Many of the dealers of interest rate options are also likely to have positions in the credit derivatives. This link between interest rate options and default spread can be useful for the risk management at the firm level.

Our results suggest that understanding the dynamic relationship between the economic variables and the shape of the smile is important for developing valuation models for interest rate options. In future research, these results should be extended to other time periods and currencies.

\section{Uncited references}

Bates (1996), Black and Scholes (1973), Brenner and Eom (1997), Brenner and Subrahmanyam (1994), Das and Sundaram (1999), Derman and Kani (1994), Dupire (1994), Granger (1969), Heynen (1993), Heynen et al. (1994), Hull and White (1987), Jackwerth (2000), Jameson and Wilhelm (1992), Liu and Longstaff (2004), Longstaff (1995), Merton (1976), Ofek et al. (2004), Rubinstein (1994), Stapleton and Subrahmanyam (2001), Wiggins (1987).

\section{Acknowledgements}

$\Lambda^{\mathrm{We}}$ thank Viral Acharya, Menachem Brenner, Rob Engle, Peter Ritchken, the editor Giorgio Szego, and participants at the finance department seminars at Case Western Reserve University, Georgia State University, Michigan State University, University of Melbourne, SMU, $_{\alpha}$ the 2004 AFA meetings in San Diego, and the 2004 Quantitative Methods in Finance conference in Syd- ney, for helpful comments and suggestions on earlier drafts. We also thank the two referees for their excellent comments and suggestions, which substantially improved the content and exposition of the paper. We thank the Fixed Income Analysts Society for the 2004 FMA Competitive Paper Award in Fixed Income. We remain responsible for all errors.

\section{References}

Backus, D, Foresi, S., Wu, L., 1997, Accounting for biases in BlackScholes, Working Paper, New York University.

Bakshi, G., Cao, C., Chen, Z., 1997. Empirical performance of alternative option pricing models. Journal of Finance 52, 2003-2049.

Bates, D.S., 1996. Jumps and stochastic volatility: Exchange rate processes implicit in Deutschemark options. Review of Financial Studies 9, 69 108.

Bates, D.S., 2000. Post-' 87 crash fears in the S\&P 500 futures option market. Journal of Econometrics 94, 181-238.

Black, F., 1976. The pricing of commodity contracts. Journal of Financial Economics 3, 167-179.

Black, F., Scholes, M., 1973. The pricing of options and corporate liabilities. Journal of Political Economy 81, 637-654.

Bollen, N.P.B., Whaley, R.E., 2004. Does net buying pressure affect the shape of the implied volatility functions? Journal of Finance 59, 711753.

Brace, A., Gatarek, D., Musiela, M., 1997. The market model of interest rate dynamics. Mathematical Finance 7, 127-155.

Brenner, M., Eom, Y.H., 1997. No-arbitrage option pricing: New evidence on the validity of the martingale property, NYU Salomon Center Working Paper.

Brenner, M., Subrahmanyam, M.G., 1994. A simple approach to-option valuation and hedging in the Black-Scholes model. Financial Analysts Journal, 25-28.

Canina, L., Figlewski, S., 1993. The informational content of implied volatility. Review of Financial Studies 6, 659-681

Carr, P., Wu, L., 2003a. The finite moment log stable process and option pricing. Journal of Finance 58, 753-777.

Carr, P., Wu, L., 2003b. What type of process underlies options? A simple robust test. Journal of Finance 58, 2581-2610.

Das, S.R., Sundaram, R., 1999. Of smiles and smirks: A term-structure perspective. Journal of Financial and Quantitative Analysis 34, $211-$ 239.

Derman, E., Kani, I., 1994. Riding on a smile. Risk 7, 32-39.

Deuskar, P., Gupta, A., Subrahmanyam, M.G. 2007. Liquidity effects in interest option markets: Premium or discount? Working paper, New York University.

Driessen, J., Klaasen, P., Melenberg, B., 2003. The performance of multifactor term structure models for pricing and hedging caps and swaptions. Journal of Financial and Quantitative Analysis 38, 635672.

Dumas, B., Fleming, J., Whaley, R.E., 1998. Implied volatility functions: Empirical tests. Journal of Finance 53, 2059-2106.

Dupire, B., 1994. Pricing with a smile. Risk 7, 18-20.

Ederington, L., Guan, W., 2002. Why are those options smiling? Journal of Derivatives 10, 9-34.

Fan, R., Gupta, A., Ritchken, P., 2003. Hedging in the possible presence of unspanned stochastic volatility: Evidence from swaption markets. Journal of Finance 58 (5), 2219-2248.

Garleanu, N., Pedersen, L.H., Poteshman, A.M., 2006. Demand-based option pricing. Working paper, University of Pennsylvania.

Granger, C., 1969. Investigating causal relations by econometric models and cross-spectral methods. Econometrica 37, 424-438.

Gupta, A., Subrahmanyam, M.G., 2005. Pricing and hedging interest rate options: Evidence from cap-floor markets. Journal of Banking and Finance 29, 701-733. 
Heynen, R., 1993. An empirical investigation of observed smile patterns. The Review of Futures Markets 13, 317-353.

Heynen, R., Kemna, A., Vorst, T., 1994. Analysis of the term structure of implied volatilities. Journal of Financial and Quantitative Analysis 29, 31-56.

Hull, J., White, A., 1987. The pricing of options on assets with stochastic volatilities. Journal of Finance 42, 281-300.

Jackwerth, J.C., 2000. Recovering risk aversion from option prices and realized returns. Review of Financial Studies 13, 433-451.

Jameson, M., Wilhelm, W., 1992. Market making in the options market and the costs of discrete hedge rebalancing. Journal of Finance 47 (2), 765-779.

Jarrow, R., Li, H., Zhao, F., 2007. Interest Rate Caps 'Smile' Too! But Can the LIBOR Market Models Capture It? Journal of Finance 62 (1), 345-382.

Li, M., Pearson, N.D., 2004, Price deviations of S\&P 500 index options from the Black-Scholes formula follow a simple pattern, Working Paper, University of Illinois.

Liu, J., Longstaff, F.A., 2004. Losing money on arbitrages: Optimal dynamic portfolio choice in markets with arbitrage opportunities. Review of Financial Studies 17, 611-641.

Longstaff, F.A., 1995. Option pricing and the martingale restriction. Review of Financial Studies 8, 1091-1124.

Longstaff, F.A., Santa-Clara, P., Schwartz, E., 2001. The relative valuation of caps and swaptions: Theory and empirical evidence. Journal of Finance 61, 2067-2109.
Mayhew, S., 2002. Competition, market structure, and bid-ask spreads in stock option markets. Journal of Finance 57, 931-958.

Merton, R., 1976. Option pricing when underlying stock distributions are discontinuous. Journal of Financial Economics 3, 125-144.

Ofek, E., Richardson, M., Whitelaw, R., 2004. Limited arbitrage and short sales restrictions: Evidence from the options markets. Journal of Financial Economics 74 (2), 305-342.

Pena, I., Rubio, G., Serna, G., 1999. Why do we smile? On the determinants of the implied volatility function. Journal of Banking and Finance 23, 1151-1179.

Pena, I., Rubio, G., Serna, G., 2001. Smiles, bid-ask spreads and option pricing. European Financial Management 7, 351-374.

Peterson, S., Stapleton, R.C., Subrahmanyam, M.G., 2003. A multi-factor spot-rate model for the pricing of interest-rate derivatives. Journal of Financial and Quantitative Analysis 38, 847-880.

Rubinstein, M., 1994. Implied binomial trees. Journal of Finance 49, 771781.

Stapleton, R.C., Subrahmanyam, M.G., 2001. The Term Structure- of Interest-Rate Futures Prices, Working Paper, New York University.

Wiggins, J.B., 1987. Option values under stochastic volatility: Theory and empirical estimates. Journal of Financial Economics 19, 351-372.

Wystup, U., 2003. The market price of foreign exchange one-touch options. Derivatives Week XII (13), 1-4. 